\title{
Noninvasive high-frequency oscillatory ventilation as respiratory support in preterm infants: a meta-analysis of randomized controlled trials
}

\author{
Jing Li, Xiaoxia Li, Xianmei Huang and Zhiqun Zhang ${ }^{*}$ (D)
}

\begin{abstract}
Background: Noninvasive high-frequency oscillatory ventilation (nHFOV), a relatively new modality, is gaining popularity despite scarce evidence. This meta-analysis was designed to evaluate the efficacy and safety of nHFOV as respiratory support in premature infants.

Methods: We searched MEDLINE, EMBASE, CINAHL, and Cochrane CENTRAL from inception of the database to January 2019. All published randomized controlled trials (RCTs) evaluating the effect of nHFOV therapy with nasal continuous positive airway pressure (nCPAP) or biphasic nCPAP (BP-CPAP) in newborns for respiratory support were included. All meta-analyses were performed using Review Manager 5.3.

Results: A total of 8 RCTs involving 463 patients were included. The meta-analysis estimated a lower risk of intubation (relative risk $=0.50,95 \%$ confidence interval of 0.36 to 0.70 ) and more effective clearance of carbon dioxide (weighted mean difference $=-4.61,95 \%$ confidence interval of -7.94 to -1.28 ) in the nHFOV group than in the nCPAP/BP-CPAP group.

Conclusions: Our meta-analysis of RCTs suggests that nHFOV, as respiratory support in preterm infants, significantly remove carbon dioxide and reduce the risk of intubation compared with nCPAP/BP-CPAP. The appropriate parameter settings for different types of noninvasive high-frequency ventilators, the effect of nHFOV in extremely preterm infants, and the long-term safety of nHFOV need to be assessed in large trials.
\end{abstract}

Keywords: Noninvasive high-frequency oscillatory ventilation, Continuous positive airway pressure, Preterm infants, Bronchopulmonary dysplasia

\section{Background}

Respiratory distress occurs in $7 \%$ of newborn infants and is increasingly common even in late preterm births [1]. Respiratory distress syndromes and infections are represented in approximately half of all cases of preterm infants [1]. Despite varied causes, the goals of managing respiratory distress include maintaining airway patency and providing respiratory support to deliver oxygen and remove carbon dioxide. In severe respiratory distress, these goals are often achieved through mechanical

\footnotetext{
* Correspondence: zhiqun.zhang@163.com

Department of Neonatology, Affiliated Hangzhou First People's Hospital,

Zhejiang University School of Medicine, China, No. 261 Huansha Road, Hangzhou City, Zhejiang 310002, China
}

ventilation [2]. Invasive mechanical ventilation (IMV) increases survival in preterm infants with severe respiratory distress syndrome (RDS) [3]. However, IMV is associated with bronchopulmonary dysplasia (BPD) and impaired neurodevelopmental outcomes in preterm infants [3, 4]. Consequently, in recent years, several methods of noninvasive ventilation, including nasal continuous positive airway pressure (nCPAP), biphasic NCPAP (BP-CPAP), nasal intermittent positive-pressure ventilation, and high-flow nasal cannula, have been used with the hopes of preventing endotracheal mechanical ventilation and BPD [5]. Unfortunately, clinical studies have shown that up to $38-42 \%$ of very low birth weight infants experience treatment failure and

(C) The Author(s). 2019 Open Access This article is distributed under the terms of the Creative Commons Attribution 4.0 International License (http://creativecommons.org/licenses/by/4.0/), which permits unrestricted use, distribution, and 
require IMV [6, 7]. Moreover, although nCPAP is increasingly used, BPD rates have not declined [3, 8]. High-frequency ventilation is considered a gentler form of IMV with superior ventilation capability [9]. Applied noninvasive high-frequency oscillatory ventilation (nHFOV) may combine the benefits of nCPAP and high-frequency ventilation, which include the absence of ventilator-patient asynchrony and high efficacy in removing carbon dioxide $\left(\mathrm{CO}_{2}\right)$ [10]. nHFOV is already used in European neonatal intensive care units despite scarce evidence to support the routine use of nHFOV [11]. Reviews of observational studies show an advantage with nHFOV for $\mathrm{CO}_{2}$ clearance in preterm infants treated for respiratory distress syndrome [12-14]. However, clinical trials could not demonstrate increased carbon dioxide clearance when applying nHFOV versus nCPAP $[15,16]$. Because of the conflicting findings from reviews of observational studies and randomized trials, we have conducted a comprehensive systematic review evaluating all evidence by collecting data from randomized trials and prospective cohort studies.

\section{Methods}

\section{Study identification and selection}

This systematic review was conducted and is reported according to the recommendations of the Preferred Reporting Items for Systematic Reviews and Meta-Analyses (PRISMA) statement [17]. Electronic searches were performed in multiple databases, including PubMed, EMBASE, the Cochrane Controlled Trials Register, the Cochrane Library, Google Scholar, VIP, and Google, for relevant articles published from inception of the databases up to January 2019. The bibliographies of all potentially relevant articles were manually searched to identify any additional articles of relevance. No language restriction was applied. In addition, experts in the field were contacted to identify any ongoing or unpublished trials, although no studies were identified by this strategy. The protocol of this systematic review was registered before the literature search in PROSPERO (Prospero2016 CRD42016053475).

\section{Eligibility criteria}

For inclusion, a study had to meet the following criteria: 1) it was a randomized controlled trial or crossover trial for evaluating interventions with a temporary effect; 2) preterm infants were randomized to receive respiratory support with nHFOV vs nCPAP/BP-CPAP; and 3) it reported more than one of the following outcome parameters: partial pressure of carbon dioxide $\left(\mathrm{pCO}_{2}\right)$ levels, $\triangle \mathrm{pCO} 2$ (variation difference of each group before crossover in randomized controlled crossover trials), and intubation. Exclusion criteria were as follows: a) non-clinical studies (experimental and basic studies); b) observational or retrospective studies; c) duplicate reports, secondary or post hoc analyses of the same study population; and d) studies with a lack of sufficient information on baseline, primary or secondary outcome data.

\section{Assessment of the risk of bias}

Two reviewers (Zhang and Li) independently assessed the risk of bias of individual studies and the bias domains across studies using the Cochrane collaboration tool [18]. All discrepancies were resolved by discussion and consensus. The studies were rated to be at high risk of bias, low risk of bias, or unclear risk of bias based on sequence generation, concealment of allocation, blinding of participants/parents and personnel, blinding of outcome assessment, incomplete outcome data, and selective outcome reporting.

\section{Data collection}

For each study, data were extracted independently by two reviewers (Zhang and $\mathrm{Li}$ ) using a predesigned form. Any differences and disagreements in the collected data were discussed and resolved by consensus. Details of methodological quality, study design, analysis, and results were noted. For each outcome, the numeric results, the statistical methods used, and the $P$ value were recorded. For randomized controlled crossover trials, because of carry-over, we only included data from the first stage for analysis. We contacted authors of the original reports to obtain further details when information regarding any of the above information was unclear.

\section{Statistical analysis}

The statistical analyses were performed by the Mantel-Haenszel method (fixed-effect model) or the DerSimonian and Laird method (random-effect model) using the Review Manager meta-analysis software (version 5.3, 2012; The Cochrane Collaboration, Copenhagen, Denmark). Treatment effect estimates for all trials were calculated and expressed as typical relative risk (RR) for dichotomous outcomes and weighted mean difference (WMD) for continuous outcomes, all with a 95\% confidence interval. The between-trial presence of heterogeneity among the recorded treatment effects was analysed by the $x^{2}$ test for heterogeneity and the $\mathrm{I}^{2}$ statistic, which expresses the proportion of heterogeneity that cannot be explained by chance. Heterogeneity was deemed significant when the corresponding $P$ value was $<0.1$ or when the $\mathrm{I}^{2}$ percentage was $>50$, at which point the random-effect model was used. Otherwise, a fixed-effect model was applied [19]. Subgroup analyses or sensitivity analyses were carried out to assess the source of heterogeneity. When more than 10 articles were included, the 
presence of publication bias was assessed and displayed through a funnel plot.

\section{Results}

\section{Study selection, description and assessment}

The search strategy resulted in 286 potentially relevant citations. The PRISMA flow diagram (Fig. 1) summarizes the process of the literature search and study selection. After screening the titles and abstracts, we read 26 full-text articles or abstracts and assessed them for eligibility. Eight RCTs $[16,20-26]$ comprising 463 participants met the inclusion criteria. Overall, 6 trials $[16,20-22,25,26]$ of nHFOV vs nCPAP as respiratory support in preterm infants included 359 infants, and 2 trials $[22,24]$ of $\mathrm{nHFOV}$ vs BP-CPAP as respiratory support included 104 infants.

\section{Characteristics of the included studies}

The 8 RCTs selected for analysis included a total of 463 participants (Tables 1, 2 and 3) [16, 20-26]. The publication dates of the RCTs ranged from 2016 to 2018. The nHFOV group vs nCPAP/BP-CPAP group were well-matched; the birth weight and gestational age did not differ significantly. Other aspects of respiratory treatment, including the resuscitation devices used and the criteria for using antenatal glucocorticoids as well as surfactant, were adequately described in the studies and conformed to current international guidelines. The incidence of neonatal respiratory distress syndrome (diagnosed based on respiratory symptoms and corresponding X-ray changes) was comparable between the nHFOV group and the nCPAP/BP-CPAP group.

\section{Risk of bias within individual studies}

The risk of bias assessment for the included RCTs $[16,20-26]$ is reported in Table 4. Two trials were randomized controlled crossover trials [16, 20]. Most studies had a moderate to high risk of bias. Most bias stemmed from the blinding of the participants and personnel and the outcome assessments. The method of randomization was determined to be adequate in all studies. Four studies were found to have adequate concealment of allocation (Table 4).

Systematic review of the findings from the collected results $p \mathrm{CO} 2$ levels, $\triangle p C O 2$, and intubation. Five trials enrolling 224 preterm infants reported pCO2 levels. Meta-analysis indicated that nHFOV significantly reduced $\mathrm{pCO} 2$ in preterm infants compared with nCPAP/BP-CPAP, including pCO2 levels $(\mathrm{WMD}=-4.61,95 \% \mathrm{CI}-7.94$ to $\left.1.28, \mathrm{I}^{2}=67 \%, P=0.007\right)$ after respiratory support and $\triangle \mathrm{pCO} 2(\mathrm{WMD}=-4.89,95 \% \mathrm{CI}-8.36$ to $-1.42, \mathrm{I} 2=$ $70 \%, P=0.006)$ before and after respiratory support (Fig. 2). Eight trials enrolling 283 preterm infants

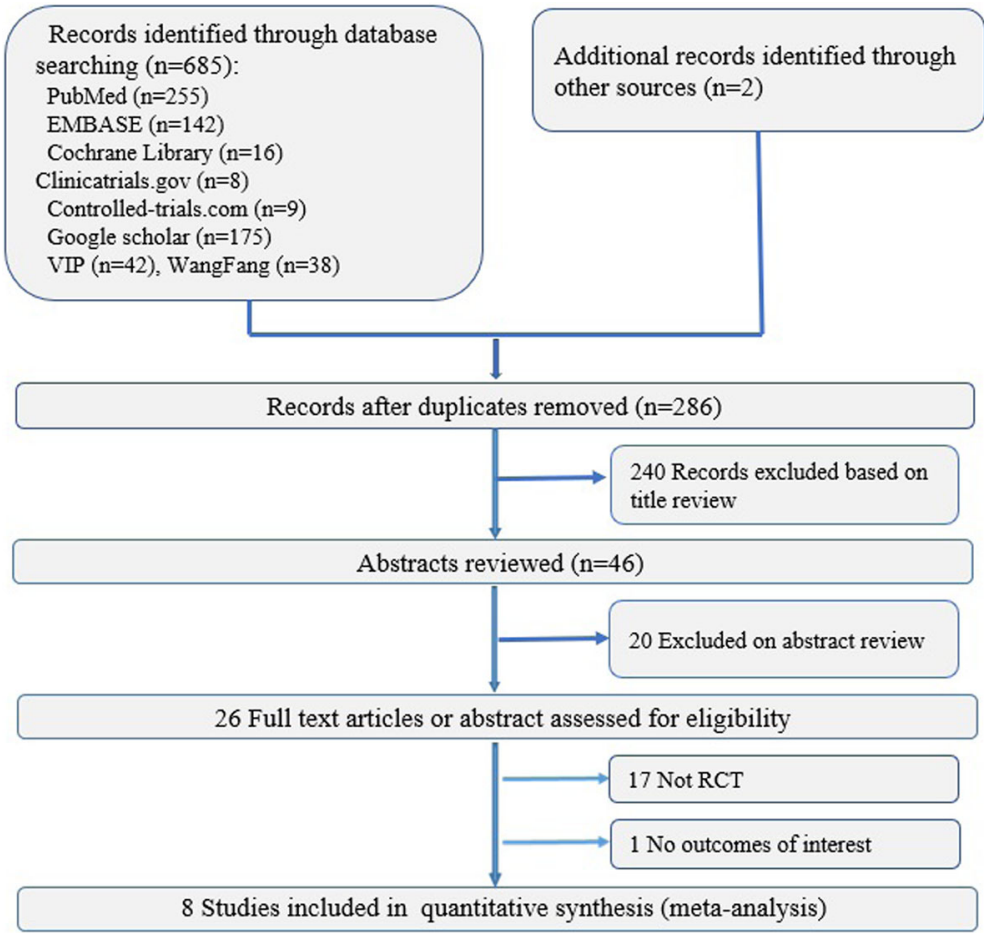

Fig. 1 A PRISMA flow chart for the selection of eligible studies 
Table 1 Characteristics of 8 RCTs and baseline characteristics of patients

\begin{tabular}{|c|c|c|c|c|c|c|c|c|c|}
\hline Study & Study design & Group & $\mathrm{N}$ & Male (n) & GA (wk) & BW (g) & $\begin{array}{l}\text { Antenatal } \\
\text { steroid }\end{array}$ & Surfactant (n) & Caffeine (n) \\
\hline \multirow[t]{2}{*}{ Bottino 2018 [20] } & \multirow{2}{*}{$\begin{array}{l}\text { Randomized controlled } \\
\text { crossover trial }\end{array}$} & nHFOV & 15 & NA & $<32$ & $<1500$ & NA & 15 & 15 \\
\hline & & nCPAP & 15 & NA & $<32$ & $<1500$ & NA & 15 & 15 \\
\hline \multirow[t]{2}{*}{ Klotz 2017 [16] } & \multirow{2}{*}{$\begin{array}{l}\text { Randomized controlled } \\
\text { crossover trial }\end{array}$} & nHFOV & 13 & 2 & $26.1(2.2)^{*}$ & $814.2(208.2)^{*}$ & 13 & 13 & 13 \\
\hline & & nCPAP & 13 & 9 & $27.2(2.0)^{*}$ & $1083.5(359.1)^{*}$ & 13 & 13 & 13 \\
\hline \multirow[t]{2}{*}{ Lou 2017 [21] } & \multirow[t]{2}{*}{ Randomized controlled trial } & nHFOV & 34 & 24 & $32.5(1.3)^{*}$ & $1790(350)^{*}$ & 13 & 34 & NA \\
\hline & & nCPAP & 31 & 22 & $32.4(1.4)^{*}$ & $1850(410)^{*}$ & 12 & 21 & NA \\
\hline \multirow[t]{2}{*}{ Lou 2018 [22] } & \multirow[t]{2}{*}{ Randomized controlled trial } & nHFOV & 33 & 18 & $33.5(1.5)^{*}$ & $1790(330)^{*}$ & 12 & 33 & NA \\
\hline & & BPCPAP & 32 & 17 & $34.2(1.6)^{*}$ & $1840(420)^{*}$ & 11 & 32 & NA \\
\hline \multirow[t]{2}{*}{ Malakian 2018 [23] } & \multirow[t]{2}{*}{ Randomized controlled trial } & nHFOV & 63 & 28 & $31.08(2.9)^{*}$ & $1485.5(470)^{*}$ & 36 & 21 & NA \\
\hline & & nCPAP & 61 & 25 & $31.07(2.8)^{*}$ & $1505.5(490)^{*}$ & 31 & 23 & NA \\
\hline \multirow[t]{2}{*}{ Mukerji 2017 [24] } & \multirow[t]{2}{*}{ Randomized controlled trial } & nHFOV & 16 & 1 & $26.1(1.3)^{*}$ & $831.9(150.1)^{*}$ & 12 & 10 & NA \\
\hline & & BPCPAP & 23 & 2 & $26.5(1.6)^{*}$ & $878.0(198.3)^{*}$ & 20 & 14 & NA \\
\hline \multirow[t]{2}{*}{ Zhu 2017 [25] } & \multirow[t]{2}{*}{ Randomized controlled trial } & nHFOV & 37 & 22 & $31.7(1.7)^{*}$ & $1670(353)^{*}$ & 13 & 37 & NA \\
\hline & & nCPAP & 39 & 21 & $32.0(1.9)^{*}$ & $1735(327)^{*}$ & 15 & 39 & NA \\
\hline \multirow[t]{2}{*}{ Zhu 2017 [26] } & \multirow[t]{2}{*}{ Randomized controlled trial } & nHFOV & 17 & 10 & $31.7(1.7)^{*}$ & $1670(353)^{*}$ & 6 & 17 & NA \\
\hline & & nCPAP & 21 & 12 & $32.0(1.9)^{*}$ & $1735(327)^{*}$ & 8 & 21 & NA \\
\hline
\end{tabular}

NA Not Applicated, $B W$ : Birth weight, *means $\pm \mathrm{SD}$

reported on the rates of intubation. Meta-analysis indicated that nHFOV was associated with a lower likelihood of intubation for mechanical ventilation within 7 days than $\mathrm{nCPAP} / \mathrm{BP}-\mathrm{CPAP}$ was $(\mathrm{RR}=0.50,95 \% \mathrm{CI} 0.36$ to $0.70, \mathrm{I} 2=0 \%, P<0.0001$ ) (Fig. 3). A sensitivity analysis restricted to studies clearly stating the positive results $[22,25]$ showed similar results $(\mathrm{RR}=0.57,95 \% \mathrm{CI}$ 0.38 to $0.87, \mathrm{I}^{2}=0 \%, P=0.009$ ).

\section{Discussion}

This meta-analysis identified 8 randomized trials with 463 premature infants that compared respiratory support with nHFOV to that with nCPAP/BP-CPAP in preterm infants. The results of this systematic review of available RCTs show that in preterm infants, the use of nHFOV rather than nCPAP/BP-CPAP was beneficial in terms of improved $\mathrm{CO}_{2}$ elimination and a reduced risk of intubation for mechanical ventilation.

The quality of systematic reviews depends on the quality of the studies included. We evaluated the risk of bias in the RCTs analysed. Methodological issues may affect the study quality. We scrutinized the selected studies for good methodologic quality using strict quality assessment criteria [27]. The present review, to the best of our knowledge, is the first meta-analysis of RCTs reporting on the use of nHFOV compared with nCPAP/BP-CPAP as respiratory support in preterm infants. As a new noninvasive respiratory support method; there are relatively few prospective studies on nHFOV for preterm infants, and most studies are retrospective studies [12-14]. Most bench studies have clarified the effectiveness of nHFOV in promoting carbon dioxide removal from intrinsic mechanical properties [28-30], and nHFOV is superior to NIPPV in lung $\mathrm{CO}_{2}$ elimination [31]. Noninvasive interfaces affect tidal volume (Tv) and $\mathrm{DCO}_{2}$, and smaller cannulae result in lower tidal volume (Tv) reaching the distal airways and less $\mathrm{CO}_{2}$ elimination $[28,29]$. Using lower frequency and higher amplitude in the nHFOV device increases $\mathrm{Tv}$ and promotes $\mathrm{CO}_{2}$ removal [30]. Similar to our meta-analysis, most retrospective studies found that nHFOV can effectively remove $\mathrm{CO}_{2}$. Van der Hoeven et al. [12] investigated the efficacy of nHFOV in a heterogeneous group of 21 infants with moderate respiratory insufficiency and showed that nHFOV was effective in reducing $\mathrm{pCO}_{2}$. Mukerji et al. [13] reported that nHFOV significantly reduces the occurrences of apnoeas, bradycardias, desaturations and $\mathrm{CO}_{2}$ levels compared with No nHFOV. nHFOV is effective in decreasing $\mathrm{pCO}_{2}$ in stable premature infants who require nasal CPAP support [14]. Recently, two RCTs by Rüegger et al. [15] (no specific data were reported) and Klotz et al. [16] showed that nHFOV fails to increase $\mathrm{CO}_{2}$ clearance compared with nCPAP in preterm infants; the former study mainly evaluated clinical symptom outcomes and included the paired difference in the combined number of episodes of desaturation and bradycardia during the 120-min period [15], and the latter study enrolled some patients who already had low $\mathrm{CO}_{2}$ [16]. Reducing $\mathrm{CO}_{2}$ levels is beneficial for severe hypercapnia, which may be harmful to maintaining normal $\mathrm{CO}_{2}$ levels [32]. Moreover, invasive 


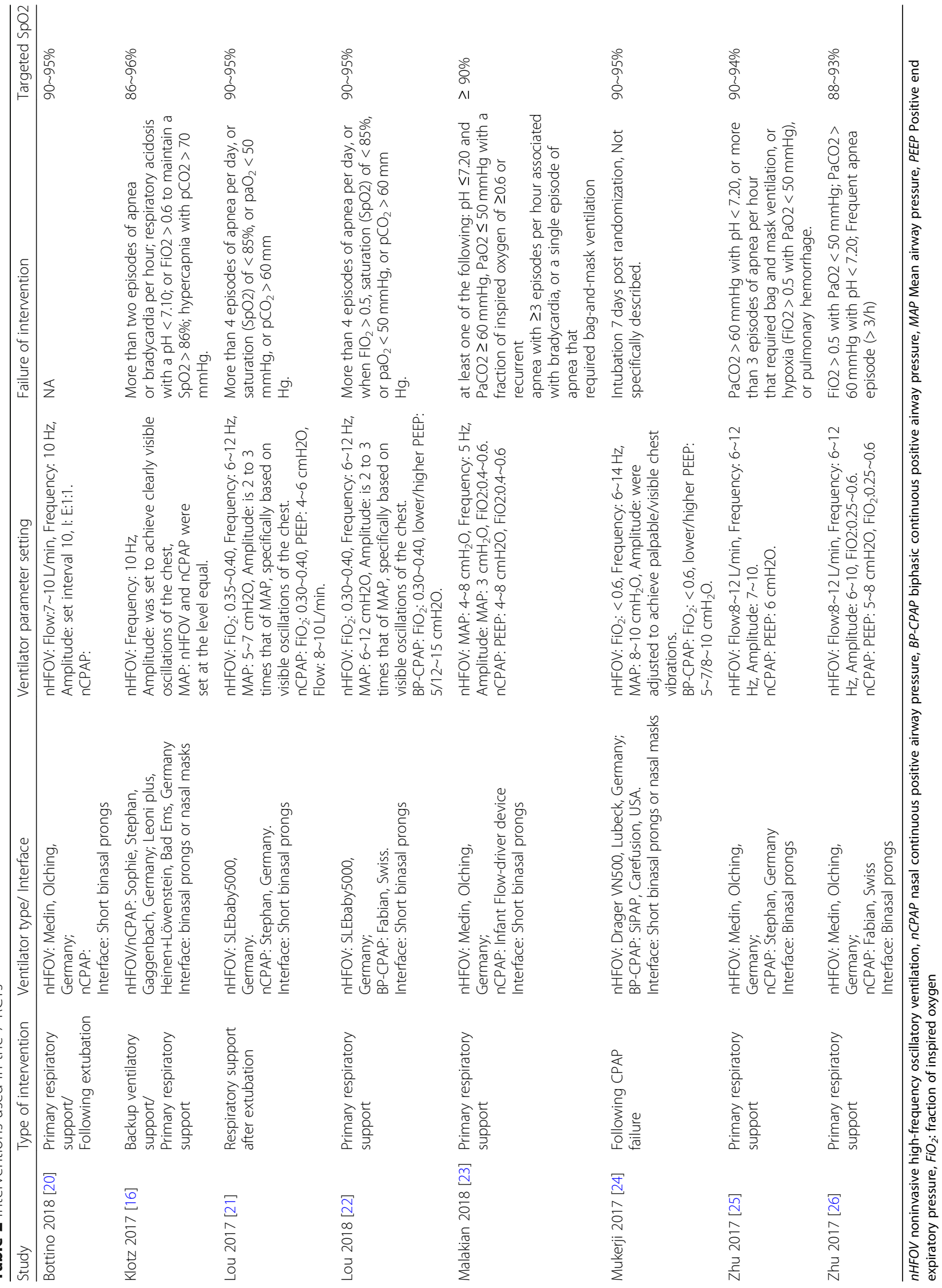


Table 3 Outcomes measured in the 7 RCTs

\begin{tabular}{lllll}
\hline Study & Group & pCO2 levels* & $\Delta \mathrm{pCO}^{*}$ & Intubation \\
\hline Bottino 2018 [20] & nHFOV & $46.6(7.5)$ & $-3.4(7.77)$ & $0 / 15$ \\
& nCPAP & $49.9(6.7)$ & $1.4(7.31)$ & $0 / 15$ \\
Klotz 2017 [16] & nHFOV & $54.8(14.6)$ & $3.6(12.66)$ & $0 / 13$ \\
& nCPAP & $49(8.1)$ & $-1(7.01)$ & $0 / 13$ \\
Lou 2017 [21] & nHFOV & $35.1(7.8)$ & $-1.4(7.85)$ & $5 / 34$ \\
& nCPAP & $40.6(7.8)$ & $2.4(7.24)$ & $12 / 31$ \\
Lou 2018 [22] & nHFOV & $41.5(6.3)$ & $-13(7.43)$ & $9 / 33$ \\
& BP-CPAP & $50.5(6.5)$ & $-3.1(7.0)$ & $10 / 32$ \\
Malakian 2018 [23] & nHFOV & & & $4 / 63$ \\
& nCPAP & & & $9 / 61$ \\
Mukerji 2017 [24] & nHFOV & NA & NA & $6 / 16$ \\
& BP-CPAP & NA & NA & $15 / 23$ \\
Zhu 2017 [25] & nHFOV & NA & NA & $9 / 37$ \\
& nCPAP & NA & NA & $22 / 39$ \\
Zhu 2017 [26] & nHFOV & $43.7(5.6)$ & $-12.1(5.08)$ & $4 / 17$ \\
& nCPAP & $48(4.7)$ & $-6.3(4.29)$ & $12 / 21$ \\
\hline
\end{tabular}

NA Not Applicated, ${ }^{*}$ means \pm SD, $\mathrm{pCO} 2$ levels refers to Post nHFOV or $n C P A P / B P-C P A P$

neonatal ventilators (Sophie, Stephan, Gaggenbach, Germany; Leoni plus, Heinen+Löwenstein, Bad Ems, Germany) can be used to make an nHFOV mode through bi-nasal prongs or nasal masks with the frequency set to $10 \mathrm{~Hz}$ [16]. Experimental and clinical observational data using nHFOV devices other than the CNO device (Medin, $\mathrm{CNO}$ ) suggest the need for much higher amplitudes at a frequency of $10 \mathrm{~Hz}$, especially for low-compliant lung disease, to have a clinically relevant effect on $\mathrm{pCO}_{2}$ [33]. Compared with the dedicated noninvasive high-frequency generator (Medin, $\mathrm{CNO}$ ), nondedicated high-frequency ventilators may be prone to air leakage or may not reach the set parameters in the airway due to lack of air leakage compensation because there is no pressure sensor. Wang et al. [34] reported that the effect of a nondedicated high-frequency ventilator (SLE5000) is similar to that of a dedicated high-frequency noninvasive generator (Medin, $\mathrm{CNO}$ ) in clearing carbon dioxide and requiring intubation; however, the mean airway pressure of a nondedicated noninvasive high-frequency ventilator (SLE5000) $(10(9,11)$ ) is significantly higher than that of a dedicated high-frequency generator (Medin, CNO) (5(5,7)) [3]. In addition, a bench study showed that the optimal frequency for $\mathrm{CO}_{2}$ removal was $8 \mathrm{~Hz}$ [31]. In addition to the results from model studies and retrospective studies, our meta-analysis that was based on randomized controlled trials also confirmed that nHFOV can significantly remove $\mathrm{CO}_{2}$. Although removing $\mathrm{CO}_{2}$ is a weak outcome and is not directly related to major clinical outcomes, infants who fail to respond to nCPAP/BP-CPAP and retain $\mathrm{CO}_{2}$ can avoid intubation altogether with nHFOV. The role of nHFOV in removing carbon dioxide seems undisputed, and we should pay more attention to the effectiveness of nHFOV in different lung diseases and the long-term effects of nHFOV, such as BPD, IVH, NEC, infancy respiratory function and neurodevelopmental outcomes.

Although retrospective studies reported the feasibility of nHFOV in preventing intubation or facilitating extubation [13, 35], four RCTs did not show that noninvasive high-frequency ventilation had significant advantages in avoiding intubation compared with nCPAP/BP-CPAP [22-24, 26]. However, our meta-analysis showed that noninvasive high-frequency ventilation can reduce the risk for intubation compared with nCPAP/BP-CPAP, and the finding was robust to sensitivity analysis. It is important to note that when trials mixed patients of different mechanical risks, inappropriate parameter settings of nHFOV may be useless. Therefore, lung mechanics may vary in different patients and in different moments during the disease course, and this may require adjustments

Table 4 Risk of Bias Assessment for Included Randomized Clinical Trials

\begin{tabular}{|c|c|c|c|c|c|c|c|c|}
\hline \multirow[t]{3}{*}{ Source } & \multicolumn{8}{|l|}{ Bias } \\
\hline & \multicolumn{2}{|l|}{ Selection } & \multirow{2}{*}{$\begin{array}{l}\text { Performance: } \\
\text { Blinding of } \\
\text { Participant } \\
\text { and } \\
\text { Personnel }\end{array}$} & \multirow{2}{*}{$\begin{array}{l}\text { Detection: } \\
\text { Blinding of } \\
\text { Outcome } \\
\text { Assessment }\end{array}$} & \multirow{2}{*}{$\begin{array}{l}\text { Attrition: } \\
\text { Incomplete } \\
\text { Outcome } \\
\text { Data }\end{array}$} & \multirow{2}{*}{$\begin{array}{l}\text { Selective } \\
\text { Reporting }\end{array}$} & \multirow{2}{*}{$\begin{array}{l}\text { Other } \\
\text { Sources }\end{array}$} & \multirow[t]{2}{*}{ Overall } \\
\hline & $\begin{array}{l}\text { Random } \\
\text { Sequence } \\
\text { Generation }\end{array}$ & $\begin{array}{l}\text { Allocation } \\
\text { Concealment }\end{array}$ & & & & & & \\
\hline Bottino 2018 [20] & Low risk & Low risk & High risk & High risk & Low risk & Low risk & Unclear risk & High risk \\
\hline Klotz 2017 [16] & Low risk & Low risk & High risk & High risk & Low risk & Unclear risk & Unclear risk & High risk \\
\hline Lou 2017 [21] & Low risk & Unclear risk & High risk & High risk & Low risk & Unclear risk & Unclear risk & High risk \\
\hline Lou 2018 [22] & Low risk & Unclear risk & High risk & High risk & Low risk & Unclear risk & Unclear risk & High risk \\
\hline Malakian 2018 [23] & Low risk & Unclear risk & High risk & High risk & High risk & Unclear risk & Unclear risk & High risk \\
\hline Mukerji 2017 [24] & Low risk & Low risk & High risk & High risk & High risk & High risk & Unclear risk & High risk \\
\hline Zhu 2017 [25] & Low risk & Low risk & Unclear risk & Unclear risk & Low risk & Unclear risk & Unclear risk & Moderate risk \\
\hline Zhu 2017 [26] & Low risk & Unclear risk & Unclear risk & Unclear risk & Low risk & Unclear risk & Unclear risk & Moderate risk \\
\hline
\end{tabular}




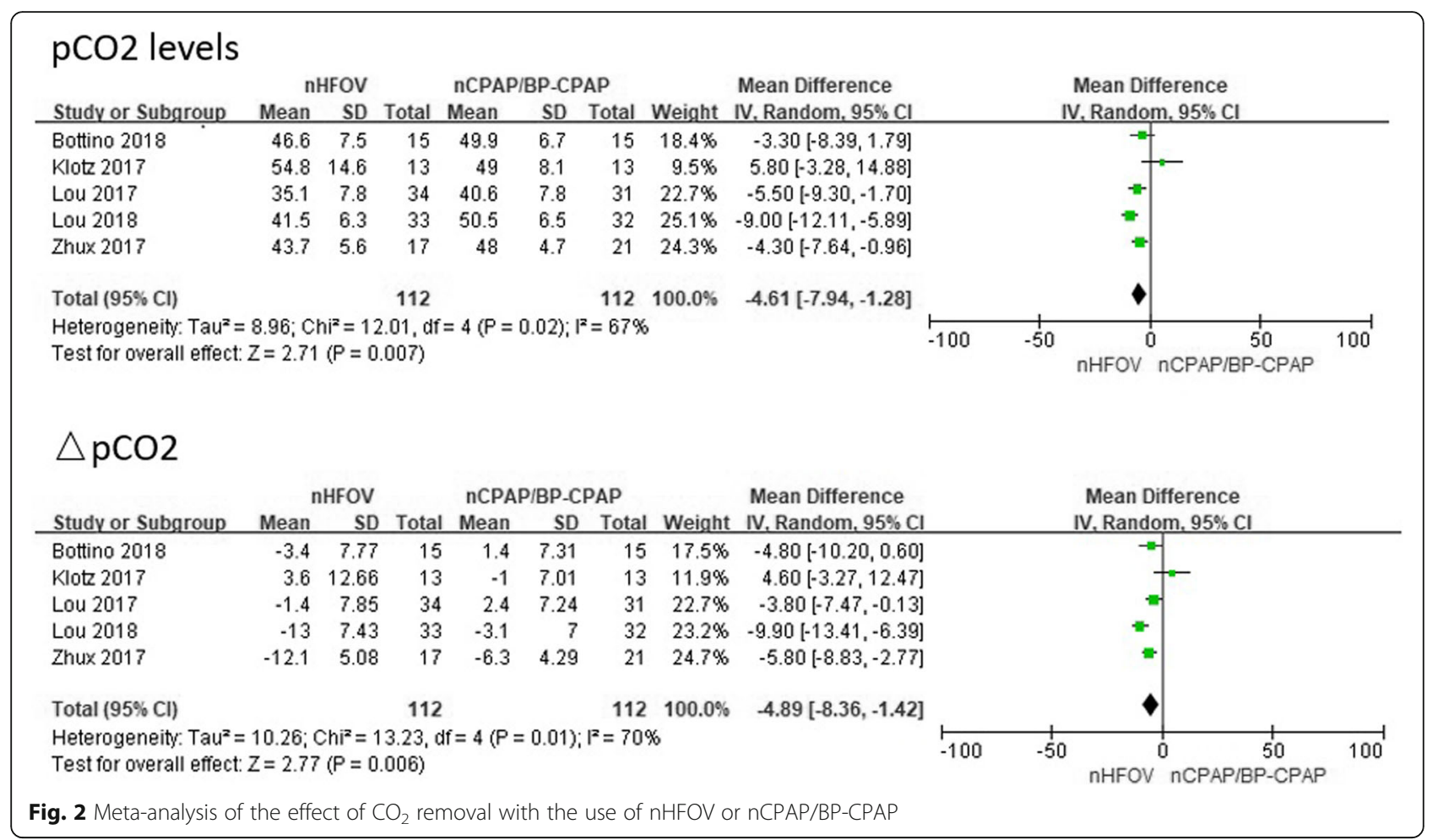

of various parameters [31]. Since $\mathrm{CO}_{2}$ elimination under nHFOV is provided in the upper airway dead-space [31], it is probably unnecessary to increase $\Delta \mathrm{P}$ to achieve a visible chest oscillation for less severely ill infants (such as those affected by RDS or TTN) [33]. However, for patients with BPD or acute-on-chronic respiratory failure, NHFOV with real oscillators at high amplitudes is possibly useful to avoid invasive ventilation [33]. This factor deserves targeted trials, which are rare and difficult to perform. Fortunately, two multi-centre trials (NCT03181958, NCT03099694) are presently ongoing to draw objective conclusions. To optimize respiratory support for different patients and different moments during the disease course, a tool to help trial designers go through explanatory and pragmatic trials is necessary $[36,37]$. In addition, the interface may affect the ventilation effect. In vitro studies show that devices with short double prongs had the lowest resistance to flow when nCPAP was used for respiratory support [38]. A bench and in vivo study showed that the amplitude of oscillation obviously decreases when the mask is used for high-frequency oscillatory ventilation [39]. Two studies

\begin{tabular}{|c|c|c|c|c|c|c|c|c|c|c|c|}
\hline Studv or Subgroup & \multicolumn{2}{|c|}{ nHFOV } & \multicolumn{2}{|c|}{ nCPAP/BP-CPAP } & Weight & $\begin{array}{c}\text { Risk Ratio } \\
\text { M-H, Fixed, } 95 \% \mathrm{Cl}\end{array}$ & \multicolumn{5}{|c|}{$\begin{array}{c}\text { Risk Ratio } \\
\text { M-H, Fixed, } 95 \% \mathrm{Cl}\end{array}$} \\
\hline Bottino 2018 & 0 & 15 & 0 & 15 & & Not estimable & & & & & \\
\hline Klot 2017 & 0 & 13 & 0 & 13 & & Not estimable & & & & & \\
\hline Lou 2017 & 5 & 34 & 12 & 31 & $16.4 \%$ & $0.38[0.15,0.96]$ & & & & & \\
\hline Lou 2018 & 9 & 33 & 10 & 32 & $13.3 \%$ & $0.87[0.41,1.86]$ & & & & & \\
\hline Malakian 2018 & 4 & 63 & 9 & 61 & $12.0 \%$ & $0.43[0.14,1.32]$ & & & & & \\
\hline Wukerji 2016 & 6 & 16 & 15 & 23 & $16.1 \%$ & $0.57[0.29,1.16]$ & & & & & \\
\hline Zhu 2017 & 9 & 37 & 22 & 39 & $28.1 \%$ & $0.43[0.23,0.81]$ & & & $\rightarrow-$ & & \\
\hline Zhux 2017 & 4 & 17 & 12 & 21 & $14.1 \%$ & $0.41[0.16,1.05]$ & & & & & \\
\hline Total $(95 \% \mathrm{Cl})$ & & 228 & & 235 & $100.0 \%$ & $0.50[0.36,0.70]$ & & & & & \\
\hline Total events & 37 & & 80 & & & & & & & & \\
\hline $\begin{array}{l}\text { Heterogeneity: } \mathrm{Chi}^{2} \\
\text { Test for overall effect }\end{array}$ & $\begin{array}{l}3.01, d f= \\
Z=4.140\end{array}$ & $\begin{array}{l}5(\mathrm{P}= \\
P=0.0\end{array}$ & $\begin{array}{l}0.70) ; I^{2}=0 \\
0001)\end{array}$ & & & & 0.01 & 0.1 & nHFOV & $\begin{array}{cc}10 \\
\text { nCPAP/BP-CPAP }\end{array}$ & 100 \\
\hline
\end{tabular}


included in our meta-analysis used nasal masks $[16,24]$. This may have affected the ventilation, including $\mathrm{CO}_{2}$ removal and intubation, in those studies.

Although 6 RCTs included in our meta-analysis reported BPD and air leak, and 5 RCTs reported IVH, because the vast majority of trials examined are small, with cross-over design and not powered for these outcomes; the population included in the RCTs is generally late preterm infants, it may affect an outcome of BPD. It is inappropriate to perform meta-analysis of these outcomes. Therefore, we believe that a large multi-centre trial is urgently needed to confirm the effect of nHFOV in extremely preterm infants and the safety of nHFOV.

Admittedly, several limitations in our meta-analysis might have affected the interpretation of the findings. The analysed trials differed in their study design and clinical characteristics of the study participants. Two of the studies we included were randomized controlled crossover trials. Although the first period of a cross-over trial is in effect a parallel group comparison, use of data from only the first period will be biased if, as is likely, the decision to do so is based on a test of carry-over [18]. There was heterogeneity in the characteristics of the participants and interventions (including types and parameter settings of the noninvasive high-frequency ventilator) and a lack of a standardized assessment of intubation risk. Due to the mechanical characteristics of nHFOV, there are no trials reporting on the training of this respiratory support; thus, there is bias created by the different expertise levels of NICU personnel in using the technique. Furthermore, our meta-analysis was limited by the overall low quality of evidence and lack of robustness in higher quality trials. Publication bias could not be ruled out using a funnel plot due to a limited number of studies. Additionally, subgroup analyses based on gestational age or birth weight could not be performed due to the lack of individual patient data. Most premature infants included in this meta-analysis had a gestational age of over 30 weeks. For preterm infants under 30 weeks of age, who are severely affected by RDS and face a high risk of BPD, nHFOV may be beneficial [40]. Other possible biases include: the use of different interfaces across the studies are known to impact on mechanical efficiency of all types of noninvasive ventilation and even for nHFOV [33]; the measure of $\mathrm{pCO} 2$ by different methods (arterial, arterialised capillary and transcutaneous) in different studies may affect the results. Some studies may use venous $\mathrm{CO} 2$ and this should be avoided. In addition to sound design and adequate sample size, future research should not ignore populations of extremely premature infants, complex respiratory physiology and evaluating comfort $[40,41]$.

\section{Conclusion}

In summary, the results of our meta-analysis of RCTs suggest that nHFOV, as respiratory support in preterm infants, significantly reduces the $\mathrm{pCO}_{2}$ level and risk for intubation compared with nCPAP/BP-CPAP. The appropriate parameter settings for different types of noninvasive high-frequency ventilators, the effect of nHFOV in extremely preterm infants, and the long-term outcome of nHFOV need to be assessed in large trials.

\section{Additional file}

Additional file 1: Figure S1. Meta-analysis of adverse outcome with the use of nHFOV or nCPAP/BP-CPAP.

\section{Abbreviations}

BP-CPAP: Biphasic continuous positive airway pressure; BPD: Bronchopulmonary dysplasia; $\mathrm{CO}_{2}$ : Carbon dioxide; FiO2: Fraction of inspired oxygen; IMV: Invasive mechanical ventilation; IVH: Intraventricular hemorrhage; MAP: Mean airway pressure; nCPAP: Nasal continuous positive airway pressure; NEC: Necrotizing enterocolitis; nHFOV: Noninvasive highfrequency oscillatory ventilation; $\mathrm{pCO}_{2}$ : Partial pressure of carbon dioxide; PEEP: Positive end expiratory pressure; PRISMA: Preferred Reporting Items for Systematic Reviews and Meta-Analyses; RCTs: Randomized controlled trials; RDS: Respiratory distress syndrome; RR: Relative risk; WMD: Weighted mean difference

Acknowledgements

Not applicable.

Consent to publication

Not applicable.

\section{Funding}

This work was supported by Natural Science Foundation of Zhejiang Province (grant number LY15H040002) and Health and Family Planning Commission of Zhejiang Province of China (grant number 2014RCA021). The funding source play no role in study design, data collection, data analysis, data interpretation, writing of the report, or in the decision to submit the report for publication.

Availability of data and materials

All data generated or analysed during this study are included in this published article (and its supplementary information files).

\begin{abstract}
Authors' contributions
Conception and design: ZQZ; Acquisition of data: ZQZ, JL, XMH; Analysis and interpretation of data: XXL, ZQZ, YZ; Drafting the article: JL, ZQZ; Revising the article critically for important intellectual content: $J, Z Q Z, X X L, X M H$; Final approval of the version to be published: JL, ZQZ, XXL, XMH; Agreement to be accountable for all aspects of the work in ensuring that questions related to the accuracy or integrity of any part of the work are appropriately investigated and resolved: JL, ZQZ, XXL, XMH. All of the authors read and approved the manuscript.
\end{abstract}

Ethics approval and consent to participate

As the paper did not involve any human or animal, the ethical approval was not required.

\section{Competing interests}

None of the investigators declare any real or perceived conflicts of interest pertaining to the subject of this manuscript. 


\section{Publisher's Note}

Springer Nature remains neutral with regard to jurisdictional claims in published maps and institutional affiliations.

Received: 27 October 2018 Accepted: 6 March 2019

Published online: 15 March 2019

\section{References}

1. Kumar A, Bhat BV. Epidemiology of respiratory distress of newborns. Indian J Pediatr. 1996;63(1):93-8

2. Sweet DG, Carnielli V, Greisen G, Hallman M, Ozek E, Plavka R, et al. European consensus guidelines on the Management of Respiratory Distress Syndrome - 2016 update. Neonatology. 2016;111:107-25.

3. Stoll BJ, Hansen NI, Bell EF, Walsh MC, Carlo WA, Shankaran S. Eunice Kennedy Shriver National Institute of Child Health and Human Development neonatal research network. Trends in care practices, morbidity, and mortality of extremely preterm neonates, 1993-2012. JAMA. 2015;314:1039-51.

4. Natarajan G, Pappas A, Shankaran S, Kendrick DE, Das A, Higgins RD, et al. Outcomes of extremely low birth weight infants with bronchopulmonary dysplasia: impact of the physiologic definition. Early Hum Dev. 2012;88:509-15.

5. Cummings JJ, Polin RA. AAP the committee on fetus and newborn. Noninvasive Respir Support Pediatr. 2016;137:e20153758.

6. Barrington KJ, Bull D, Finer NN. Randomized trial of nasal synchronized intermittent mandatory ventilation compared with continuous positive airway pressure after extubation of very low birth weight infants. Pediatrics. 2001;107:638-41.

7. Stefanescu BM, Murphy WP, Hansell BJ, Fuloria M, Morgan TM, Aschner JL. A randomized, controlled trial comparing two different continuous positive airway pressure systems for the successful extubation of extremely low birth weight infants. Pediatrics. 2003;112:1031-8.

8. Shah PS, Sankaran K, Aziz K, Allen AC, Seshia M, Ohlsson A, et al. Canadian neonatal network. Outcomes of preterm infants of 29 weeks gestation over 10-year period in Canada: a cause for concern? J Perinatol. 2012;32:132-8.

9. Pillow JJ. High-frequency oscillatory ventilation: mechanisms of gas exchange and lung mechanics. Crit Care Med. 2005;33(3 Suppl):135-41.

10. Hadj-Ahmed MA, Samson N, Nadeau C, Boudaa N, Praud JP. Laryngeal muscle activity during nasal high-frequency oscillatory ventilation in nonsedated newborn lambs. Neonatology. 2015;107:199-205.

11. Fischer HS, Bohlin $\mathrm{K}$, Bührer $\mathrm{C}$, et al. Nasal high-frequency oscillation ventilation in neonates: a survey in five European countries. Eur J Pediatr. 2015;174:465-71.

12. van der Hoeven $M$, Brouwer $E$, Blanco CE. Nasal high frequency ventilation in neonates with moderate respiratory insufficiency. Arch Dis Child Fetal Neonatal Ed. 1998;79:61-3.

13. Mukerii A, Singh B, Helou SE, Fusch C, Dunn M, Belik J, et al. Use of noninvasive high-frequency ventilation in the neonatal intensive care unit: a retrospective review. Am J Perinatol. 2015;30:171-6.

14. Colaizy TT, Younis UM, Bell EF, Klein JM. Nasal high-frequency ventilation for premature infants. Acta Paediatr. 2008:97:1518-22.

15. Rüegger CM, Lorenz L, Kamlin COF, Manley BJ, Owen LS, Bassler D, et al. The effect of noninvasive high-frequency oscillatory ventilation on desaturations and bradycardia in very preterm infants: a randomized crossover trial. J Pediatr. 2018;201:269-73.

16. Klotz D, Schneider H, Schumann S, Mayer B, Fuchs H. Non-invasive highfrequency oscillatory ventilation in preterm infants: a randomised controlled cross-over trial. Arch Dis Child Fetal Neonatal Ed. 2018;103:1-5.

17. Moher D, Liberati A, Tetzlaff J, Altman DG. PRISMA Group Preferred reporting items for systematic reviews and meta-analyses: the PRISMA statement. BMJ. 2009;339:b2535.

18. Higgins JP, Green S. Cochrane handbook for systematic reviews of interventions version 5.1.0. 2011. The Cochrane Collaboration.

19. Higgins JP, Thompson SG. Quantifying heterogeneity in a meta-analysis. Stat Med. 2002;21:1539-58.

20. Bottino R, Pontiggia F, Ricci C, Gambacorta A, Paladini A, Chijenas V, et al. Nasal high-frequency oscillatory ventilation and $\mathrm{CO} 2$ removal: a randomized controlled crossover trial. Pediatr Pulmonol. 2018;53:1245-51.

21. Lou WB, Zhang WX. Noninvasive high-frequency oscillatory ventilation versus nasal continuous positive airway pressure in premature infants with respiratory distress syndrome after weaning: A randomized controlled trial. Guangdong Med J. 2017;38:2037-40.
22. Lou WB, Zhang WX, Yuan L, Zhang B. Comparative study of noninvasive high-frequency oscillatory ventilation and bilevel positive airway pressure ventilation for preterm infants with respiratory distress syndrome. Chinese Gen Prac. 2018;21:1983-8 http://123.57.154.95:8088/zgqkyx/fileup/HTML/ 181616.shtml.

23. Malakian A, Bashirnezhadkhabaz S, Aramesh MR, Dehdashtian M. Noninvasive high-frequency oscillatory ventilation versus nasal continuous positive airway pressure in preterm infants with respiratory distress syndrome: a randomized controlled trial. J Matern Fetal Neonatal Med. 2018. https://doi.org/10.1080/14767058.2018.1555810.

24. Mukerii A, Sarmiento K, Lee B, Hassall K, Shah V. Non-invasive highfrequency ventilation versus bi-phasic continuous positive airway pressure (BP-CPAP) following CPAP failure in infants <1250 g: a pilot randomized controlled trial. J Perinatol. 2017;37:49-53.

25. Zhu XW, Zhao JN, Tang SF, Yan J, Shi Y. Noninvasive high-frequency oscillatory ventilation versus nasal continuous positive airway pressure in preterm infants with moderate-severe respiratory distress syndrome: a preliminary report. Pediatr Pulmonol. 2017;52:1038-42.

26. Zhu XW, Yan J, Ran Q, Gao QY, Liao CH, Shi Y. Noninvasive high-frequency oscillatory ventilation versus for respiratory distress syndrome in preterm infants: a preliminary report. Chin J Neonatol. 2017;32:291-4 http://www. cjneo.org.cn/CN101451201704/999695.htm.

27. Higgins JP, Altman DG, Gøtzsche PC, Jüni $P$, Moher D, Oxman AD, et al. Cochrane Bias methods group; Cochrane Statistical Methods Group The Cochrane Collaboration's tool for assessing risk of bias in randomised trials. BMJ. 2011:343:5928.

28. De Luca D, Carnielli VP, Conti G, Piastra M. Noninvasive high frequency oscillatory ventilation through nasal prongs: bench evaluation of efficacy and mechanics. Intensive Care Med. 2010;36:2094-100.

29. De Luca D, Piastra M, Pietrini D, Conti G. Effect of amplitude and inspiratory time in a bench model of non-invasive HFOV through nasal prongs. Pediatr Pulmonol. 2012;47:1012-8

30. Pillow JJ, Wilkinson $\mathrm{MH}$, Neil HL, Ramsden CA. In vitro performance characteristics of high-frequency oscillatory ventilators. Am J Respir Crit Care Med. 2001;164:1019-24.

31. Mukerji A, Finelli M, Belik J. Nasal high-frequency oscillations for lung carbon dioxide clearance in the newborn. Neonatology. 2013:103:161-5.

32. Thome UH, Genzel-Boroviczeny O, Bohnhorst B, Schmid M, Fuchs H, Rohde O. Permissive hypercapnia in extremely low birthweight infants (PHELBI): a randomised controlled multicentre trial. Lancet Respir Med. 2015;3:534-43.

33. De Luca D, Dell'Orto V. Non-invasive high-frequency oscillatory ventilation in neonates: review of physiology, biology and clinical data. Arch Dis Child Fetal Neonatal Ed. 2016;101:565-70.

34. Wang $C$, Liping $S$, Ma $X$, Lin $H, X u Y$, Lizhong D. Use of noninvasive highfrequency oscillatory ventilation in very birth weight infants. Chin J Pediatr. 2017;55:177-81.

35. Aktas S, Unal S, Aksu M, Ozcan E, Ergenekon E, Turkyilmaz C, et al. Nasal HFOV with Binasal cannula appears effective and feasible in ELBW newborns. J Trop Pediatr. 2016;62:165-8.

36. Thorpe KE, Zwarenstein M, Oxman AD, et al. A pragmatic-explanatory continuum indicator summary (PRECIS): a tool to help trial designers. J Clin Epidemiol. 2009:62:464-75.

37. De Luca D, Harrison DA, Peters MJ. 'Lumping or splitting' in paediatric acute respiratory distress syndrome (PARDS). Intensive Care Med. 2018:44:1548-50.

38. De Paoli AG, Morley CJ, Davis PG, Lau R, Hingeley E. In vitro comparison of nasal continuous positive airway pressure devices for neonates. Arch Dis Child Fetal Neonatal Ed. 2002:87:42-5.

39. De Luca D, Costa R, Visconti F, Piastra M, Conti G. Oscillation transmission and volume delivery during face mask-delivered HFOV in infants: bench and in vivo study. Pediatr Pulmonol. 2016;51:705-12.

40. Fischer HS, Rimensberger PC. Early noninvasive high-frequency oscillatory ventilation in the primary treatment of respiratory distress syndrome. Pediatr Pulmonol. 2018:53:126-7.

41. De Luca D. Noninvasive high-frequency ventilation and the errors from the past: designing simple trials neglecting complex respiratory physiology. J Perinatol. 2017:37:1065-6. 